\title{
Genetically Modified Foods and Health Concerns
}

\author{
Ali Motevallizadeh Ardekani ${ }^{1, *}$ \\ ${ }^{1}$ National Institute of Genetic Engineering and Biotechnology, Tehran, I.R. IRAN \\ ${ }^{*}$ Corresponding author: Ali Motevallizadeh Ardekani, National Institute of Genetic Engineering and Biotechnology, Tehran, I.R. IRAN. Tel: +98-2144580396, Fax: +98-2144580399, E- \\ mail:Ardekani@nigeb.ac.ir
}

Received: April 16, 2014; Revised: April 19, 2014

Keywords: Organisms; Genetically Modified; Biotechnology; Virus

In recent years, biotechnology has provided the possibility of creating genetically modified (GM) organisms by transferring genes from sources such as viruses, bacteria, animals, and plants into usually unrelated species. This ability to overcome insurmountable physiological barriers by exchanging genetic materials among all living organisms is a double-edged sword. On the one hand, it allows the creation of organisms desired and designed by humans and on the other hand, it provides an opportunity for undesired spread of genetically altered forms of organisms across the planet endangering other life forms.

Presently, the GM crops on the global market have been genetically manipulated to express basic traits such as resistance to insects or viruses, tolerance to certain herbicides, and nutritionally enhanced quality (1). More than 148 million hectares of farmland are under cultivation for GM crops throughout the world (2). Although industrial countries (United States and Canada) are the major producers of GM crops, developing countries such as China and Argentina are very active in this field. In the United States, more than 70\% of maize, cotton, and soya are biotechnological varieties (3) and in Canada, more than $70 \%$ of the processed food products are genetically engineered (4). Reports indicate that GM crop adoption rate is much higher among the developing than industrialized countries (21\% and 9\%, respectively) and this is due to the hope these countries have to alleviate hunger and poverty. Developing countries currently account for less than $50 \%$ of the global farmlands used for the GM crop cultivation but is predicted to increase to more than 200 million hectares of lands and to include 40 countries by 2015 (3).

Most of the debates on agricultural biotechnology center around the potential risks of the GM crops to human health. Some of the health risks include antibiotic re- sistance, allergenicity, nutritional changes, and the formation of toxins (5). The GM crops are alive and can migrate and spread worldwide; therefore, it is best for the agricultural biotechnology industry to proceed with caution to avoid causing unintended harm to the human health and the environment. This is especially true in the developing countries where limited capacities and infrastructure to face health and environmental disasters exist. In recent years, Cartagena protocol has introduced laws and guidelines and has obliged countries and companies to obey them in the areas of production, handling, and consumption of GM materials; however, it is mainly the responsibility of the national governments to enforce the laws within the borders of a country. The National Institute of Genetic Engineering and Biotechnology (NIGEB) in Iran should play an important role in providing the necessary information for the legislators to assist them in passing the laws for regulation of this important area in agricultural biotechnology.

\section{Acknowledgements}

There is no acknowledgment

\section{Financial Disclosure}

There was no financial interest.

\section{Funding/Support}

There was no financial interest.

\section{References}

1. Maghari BM, Ardekani AM. Genetically modified foods and social concerns. Avicenna J Med Biotechnol. 2011;3(3):109-17.

2. Knight B. Agricultural biotechnology in Europe. Crop Protection Monthly. 2007. Available from: http://www.crop-protectionmonthly.co.uk.

3. Global Biotech Area Surges Past 100 Million Hectares on 13 Percent 


\section{Motevallizadeh Ardekani A}

Growth. USA: International Service for the Acquisition of Agri. Biotech Applications ISAAA; 2007. Available from: http://www. bionity.com/en/news/61027/.

4. Improving the Regulation of Genetically Modified Foods and Other Novel Foods in Canada. canada: Report to the Government of Can- ada Biotechnology Ministerial Coordinating Committee; 2002.

5. Pusztai A. Genetically Modified Foods: Are They a Risk to Human Animal Health?: ActionBioscience; 2001. Available from: http:/| www.ask-force.org/web/Pusztai/Pusztai-GM-Foods-Risk-HumanAnimal-Health-2001.pdf. 